\title{
Critical review of encapsulation methods for stabilization and deliv- ery of astaxanthin
}

\author{
Nauman Khalid ${ }^{\mathrm{a}, \mathrm{b}}$ and Colin J. Barrow ${ }^{\mathrm{a}^{*}}$ \\ ${ }^{a}$ Centre for Chemistry and Biotechnology, Deakin University, Waurn Ponds, Victoria 3217, Australia \\ ${ }^{b}$ School of Food and Agricultural Sciences, University of Management and Technology, Lahore 54000, Pakistan \\ ${ }^{*}$ Corresponding author: Colin J. Barrow, Centre for Chemistry and Biotechnology, Deakin University, Geelong, Victoria 3217 , Australia. \\ Tel: +61 352271318; Fax: +61 352271040; E-mail: cbarrow@deakin.edu.au \\ DOI: $10.31665 /$ JFB.2018.1129 \\ Received: October 24, 2017; Revised received \& accepted: January 23, 2018 \\ Citation: Khalid, N., and Barrow, C.J. (2018). Critical review of encapsulation methods for stabilization and delivery of astaxanthin. J. Food \\ Bioact. 1: 104-115.
}

\begin{abstract}
Astaxanthin is an important carotenoid pigment and potent antioxidant with proven health benefits. It is primarily obtained from algae or bacteria and is the natural colorant in crustaceans and salmonids. However, this pigment readily degrades in the presence of light and oxygen and has low absorption rates in the human digestive system. Different encapsulation strategies have been adopted to improve astaxanthin physical stability and bioavailability for nutritional use. This review summarizes and compares different encapsulation techniques and matrices applied to astaxanthin. Typical methods for encapsulation include high pressure homogenization, nano dispersions, liposomes and nanoparticles. More recently low energy methods like membrane and microchannel emulsification have been used to improve astaxanthin stability and delivery. Despites the use of numerous delivery methods, improved delivery systems for concentrated astaxanthin formulations are still required. In addition, not all methods have undergone comprehensive in vivo studies that are required to assure the bioavailability of encapsulated astaxanthin.
\end{abstract}

Keywords: Astaxanthin; encapsulation; high energy methods; nanodispersions; bioavailability; food matrices.

\section{Introduction}

Astaxanthin is a natural carotenoid pigment, synthesized by some marine microorganisms and concentrated in higher order marine animals (Lorenz and Cysewski 2000). The main commercial sources of astaxanthin are microalgae and crustaceans (Ambati et al. 2014). The microalgae Haematococcus pluvialis, Botryococcus braunii, Chlorella zofingiensis and Chlorococcum spp. are the richest sources of astaxanthin(Johnson and An 1991). Haematococcus pluvialis has the highest concentration of ketocartenoid astaxanthin, at up to $2.0-3.0 \%(\mathrm{w} / \mathrm{w})$ on a dry weight basis(Lemoine and Schoefs 2010). Haematococcus pluvialis, under stress conditions of light intensity and phosphate deprivation, accumulates astaxanthin and its fatty acid ester derivatives(Boussiba and Vonshak 1991). Astaxanthin can reduce skin DNA damages and is a powerful antioxidant. The antioxidative activity of astaxanthin on cells is greater than that of vitamin $\mathrm{C}$ and $\mathrm{E}$, lutein, $\beta$-carotene, lycopene orcatechins (Naguib 2000). Moreover, the antioxidative activity of astaxanthin is 100 - to 500 -fold greater than $\alpha$-tocopherol (Naguib 2000). Around the mid-1990's a range of companies began to market astaxanthin as a natural dietary supplement. These companies include Soft Gel Technologies, Inc., Mera Pharmaceuticals, La Haye Laboratories and Cyanotech in the USA, Britannia Healthin the UK and Itano in Japan.

Astaxanthin contains two terminal rings joined by a conjugated polyene system and the two-asymmetric carbons located at the 3 , $3^{\prime}$ positions of the benzenoid ring contain hydroxyl groups $(-\mathrm{OH})$ and at $4,4^{\prime}$ positions haveketo $(=\mathrm{O})$ groups, on the either end of the molecule. Astaxanthin exists in three configurational isomers, two enantiomers (3S, 3'S and 3R, 3'R) and in meso form (3R, 3'S) (Fig. 1) (Higuera-Ciapara et al. 2006). Among these isomers, the $3 \mathrm{~S}, 3^{\prime} \mathrm{S}$ is the most abundant in nature and Haematococcus sp. 
<smiles>CC1=C(/C=C/C(C)=C/C=C/C(C)=C/C=C/C=C(C)/C=C/C=C(C)/C=C/C2=C(C)C(=O)C(O)CC2(C)C)C(C)(C)CC(O)C1=O</smiles>
(3S, 3'S) all-trans astaxanthin<smiles>CC1=C(/C=C/C(C)=C/C=C/C=C(C)/C=C/C=C(C)/C=C/C=C(C)/C=C/C2=C(C)C(=O)[C@@H](O)CC2(C)C)C(C)(C)C[C@H](O)C1=O</smiles>
$\left(3 R, 3^{\prime} R\right)$ all-trans astaxanthin<smiles>CC1=C(/C=C/C(C)=C/C=C/C(C)=C/C=C/C(C)=C/C=C/C=C(C)/C=C/C2=C(C)C(=O)[C@@H](O)CC2(C)C)C(C)(C)CC(O)C1=O</smiles>
(3S, 3'R) all-trans astaxanthin<smiles>CC1=C(/C=C/C(C)=C/C=C/C(C)=C/C=C/C=C(C)/C=C/C=C(C)/C=C/C2=C(C)C(=O)[C@@H](O)CC2(C)C)C(C)(C)C[C@H](O)C1=O</smiles>

(3R, 3'S) all-trans astaxanthin

Figure 1. Configuration of different astaxanthin isomersin the trans form.

synthesizes the (3S,3'S)-isomer(Visser et al. 2003). However, the synthetic form contains a racemic mixture of the two enantiomers plus the meso form, in a ratio of 1:2:1 of isomers of $\left(3 \mathrm{~S}, 3^{\prime} \mathrm{S}\right)(3 \mathrm{R}$, 3'S) and (3R, 3'R).

Depending upon the source and origin, astaxanthin is often esterified at the $-\mathrm{OH}$ with different fatty acids, particularly palmitic, oleic and linoleic acid, and so exists as the mono or diesters. Synthetic astaxanthin is in the free form, while microalgae extracted astaxanthin contain mixture of mono and diesters as shown in Fig. 2. Astaxanthin has the molecular formula $\mathrm{C}_{40} \mathrm{H}_{52} \mathrm{O}_{4}$. Its molar mass is $596.84 \mathrm{~g} / \mathrm{mol}$.

Commercially astaxanthin is mainly produced from cultured Haematococcus pluvialis. Currently, Mera pharmaceuticals and Cyanotech are the largest cultivators of Haematococcus pluvialis in North America, while Fuji Chemical Industries Ltd. Japan is the largest one in Asia and has indoor facilities in Sweden and Hawaii. ALGA technologies from Israel produces astaxanthin in solar powered photobioreactors in a closed, strictly controlled system (Wiener et al. 2003).

Harvesting of astaxanthin is done at the red stage for maximum astaxanthin concentration and the algal cells are then dried for extraction. The cells are usually extracted by settling and centrifugation. Finally, the dried product can be directly encapsulated or the astaxanthin extracted can be included in nutraceutical formulations (Olaizola and Huntley 2003).

\section{Applications and health benefits of astaxanthin}

Astaxanthin has been used in a range of applications as an antioxidant, in fish (salmon and trout) feeds, and in human health as a nutraceutical. Commercial astaxanthin acts as an anti-inflammatory agent and the effectiveness is similar to that of inflammatory drugs like aspirin or ibuprofen. In vitro experiments, in vivo pre-clinical<smiles>CC1=C(/C=C/C(C)=C/C=C/C(C)=C/C=C/C=C/C(C)=C/C=C/C(C)=C/C=C(/C(=O)OC(C)(C)C)C(C)(C)C)C(C)(C)CC(O)C1=O</smiles>

Free astaxanthin<smiles>[R]C(=O)OC1CC(C)(C)C(=CC=C(C)C=CC=C(C)C=CC=CC(C)=CC=CC(C)=CC=CC2=C(C)C(=O)C(O)CC2(C)C)C(C)=C1C</smiles><smiles>[R]C(=O)OC1C=C(C)C(/C=C/C(C)=C/C=C/C(C)=C/C=C/C(C)=C/C=C/C=C(C)/C=C/C=C(C)/C=C(\C)C2(C)CC(OC([R])=O)C(=O)C(C)=C2C)C(C)(C)C1</smiles>

Astaxanthin diester

Figure 2. Free astaxanthin, mono and diester forms of astaxanthin (Miao et al. 2006).

studies and early-stage clinical trials indicate that astaxanthin itself, or in conjunction with other components, may prevent or even curesome disorders.

Astaxanthin is utilized in nutraceutical, food, feed and pharmaceuticals. The majority of axtaxanthin used in feed is synthetic, however naturally produced astaxanthin is preferred in food due to its isomeric purity. Astaxanthin in the market is available in different delivery vehicles including energy drinks, capsules, creams, biomass, tablets, soft gels and extracts. In some commercial applications staxanthin is combined with other functional compounds like other carotenoids, multivitamins, omega- 3 fatty acids or herbal extracts. Numerous patents exist that depict functional attributes of these nutraceutical products. There is not Recommended Daily Intake (RDI) for astaxanthin, but nutritional products provided doses up do $300 \mathrm{mg}$ per day based on clinical studies. Functional foods normally contain significantly lower amounts since they normally do not aim to provide a daily amount in a single serving. Dietary supplements containing lipid extracts of Haematococcus pluvialis containing varying levels of astaxanthin are marketed worldwide, and were approved by the United States Food and Drug Administration (USFDA) as a New Dietary Ingredient in 1999. They are now marketed for use in dietary supplements in many countries.

Astaxanthin is very effective in the treatment of ocular inflammation (Suzuki et al. 2006) and also prevents skin inflammation and thickness against UV radiation (Hama et al. 2012; Santos et al. 2012). Moreover, a supercritical carbon dioxide extract of Haematococcous algaewas shown to be effective against sunburn over a period of two weeks. Also, feed antioxidant potential increased significantly after addition of astaxanthin in the diet of rabbits (Augusti et al. 2012), with a similar effect observed after astaxanthin incorporation in the diet after ethanol induced gastric ulcer in rats (Kamath et al. 2008). Astaxanthin and its esters also have anti-lipid peroxidation activity and inhibited $80 \%$ lipid peroxidation in rats with induced skin cancer (Kamath et al. 2008) and gastric ulcers. Astaxanthin addition in the diet improved diabetes symptoms by protecting pancreatic $\beta$-cells against glucose toxicity and also prevented diabetic nephropathy(Kim et al. 2009; Manabe et al. 2008). Moreover astaxanthin in combination with $\alpha$-tocopherol inhibited oxidative stress in streptozotocin-diabetic rats (Nakano et al. 2008). 


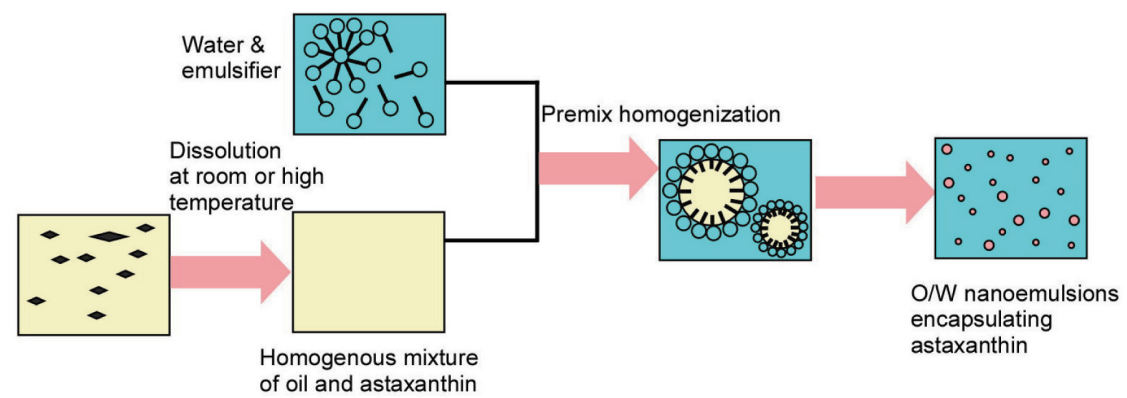

Figure 3. Systematic presentation of astaxanthin encapsulation using a two-step homogenization procedure.

Astaxanthin improved heart functionality, with the addition of $0.08 \%$ astaxanthin in mice diet increasing the functionality of heart mitochondrial membrane and contractility index in comparison to a control (Gross and Lockwood 2005). Similarly, astaxanthin had a strong effect on blood pressure reduction in normotensive Wistar Kyoto rats, spontaneously hypertensive rats and stroke prone spontaneously hypertensive rats (Monroy-Ruiz et al. 2011). Astaxanthin at the dosages of $100 \mathrm{mg}$ and $500 \mathrm{mg} / 100 \mathrm{~g}$ also restricted the activity of oxidative stress enzymes that in turn improves heart functionality (Augusti et al. 2012).

Astaxanthin and its derivatives have excellent antitumor activity in comparison to other carotenoids like $\beta$-carotene and canthaxanthin (Chew and Park 2004; Chew et al. 1998). Astaxanthin inhibited the growth of embryonic fibroblasts, prostate cancer cells, breast cancer cell and also restricted the growth of fibrosarcoma (Palozza et al. 2009). Carcinogenesis and mouse skin papillomas were significantly inhibited by astaxanthin treatment (Maoka et al. 2012). Moreover, astaxanthin extracts inhibited the growth of human colon cancer cells by stopping cell cycle progression and promoting apoptosis (Palozza et al. 2009).

\section{Encapsulation processes for astaxanthin}

Encapsulation technology can be very effective for enhancing the solubility, stability and bioavailability of astaxanthin. Astaxanthin stability and bioavailability is significantly improved by different encapsulated products and formulations (Anarjan et al. 2011a; Anarjan et al. 2014b; McClements et al. 2014; McClements and Rao 2011; Pu et al. 2011; Ribeiro et al. 2005; Tachaprutinun et al. 2009).Physicochemical properties such as stability is also improved by encapsulation. This review summarizes and compares different encapsulation strategies and formulations for enhancing stability and bioavailability of astaxanthin.

Cost-effective astaxanthin encapsulation formulations include different emulsions, colloidal dispersions, suspensions and nanoparticles. These formulations are applied in food, pharmaceutical and nutraceutical products. However, the development and optimization of these formulations is not straight forward, as emulsifier concentration, heating temperature and $\mathrm{pH}$ impact the production, storage stability and bioavailability of astaxanthin formulations. Moreover, slight changes in droplet/particle size can give different color shades and impacts the final look and feel of the product(Higuera-Ciapara et al. 2004; McClements 2012; Ribeiro et al. 2010).

\subsection{Oil in water $(O / W)$ emulsions}

Oil-in-water $(\mathrm{O} / \mathrm{W})$ emulsions contain mixtures of dispersed and continuous phase in a well-defined volume fraction. In $\mathrm{O} / \mathrm{W}$ emulsions, astaxanthin is dissolved in the oil phase and constitutes the dispersed phase, where this dispersed phase can be produced by various emulsification processes. Delivery as emulsions may increase the absorption of astaxanthin both in vitro and in vivo, depending upon the droplet size. Moreover, the solubility and disperse-ability of astaxanthin is significantly improved in emulsified form. Sub-micron emulsified droplets are stable against coalescence and sedimentation over long term storage. Different homogenization techniques are used to encapsulate astaxanthin, these include high pressure homogenization, membrane emulsification, microchannel emulsification and phase inversion temperature (PIT). The effectiveness of these processes is described below.

\subsubsection{High pressure homogenization}

Astaxanthin like other carotenoids needs a specific temperature range for solubility, and to avoid crystallization and degradation (Ribeiro et al. 2005). Moreover, the kinetics of droplet breakup and stabilization by high pressure homogenization requires an optimum interfacial balance to avoid coalescence(Khalid et al. 2017b; McClements and Rao 2011). A two-step homogenization procedure is adopted to produce fine droplets of astaxanthin loaded emulsions (Fig. 3). The first step involves production of a premix emulsion either by rotor-stator homogenization or simply by stirring. This premix is later passed through high pressure homogenization in order to get fine emulsion droplets(Khalid et al. 2017b; Ribeiro et al. 2010; Affandi et al. 2011).

The astaxanthin loaded dispersed phase is produced by dissolving astaxanthin in different vegetable oils or medium chain triacylglycerols (MCT) with heating to over $100{ }^{\circ} \mathrm{C}$ (Fig. 4a). Temperature reduction and fluctuation is an important step in avoiding degradation of astaxanthin, as high temperature results in interconversion of isomeric forms of astaxanthin (Fig. 4b). The reduction in temperature should be as fast as possible to increase the efficiency of encapsulation. A range of studies have been conducted to encapsulate astaxanthin using high pressure homogenization. Recently, Khalid et al. encapsulated different astaxanthin extracts in nanoemulsions via two step high pressure homogenization using modified lecithin and sodium caseinate as emulsifiers. The formulated nanoemulsions at $100 \mathrm{MPa}$ have droplet sizes < $170 \mathrm{~nm}$ and have encapsulation efficiency $>70 \%$ after 30 days of storage(Khalid et al. 2017b). Sotomayor-Gerding et al. (2016) encapsulated $0.5 \%$ purified astaxanthin in linseed loaded $\mathrm{O} / \mathrm{W}$ nanoemulsions with varying speed of homogenization from 5 to 100 $\mathrm{MPa}$ and significant reduction of droplet size was observed at 100 MPa with an average droplet diameter of $134 \mathrm{~nm}$. The astaxanthin nanoemulsions were stable against a range of environmental stress. In another study, supercritical extracted astaxanthin was encapsu- 

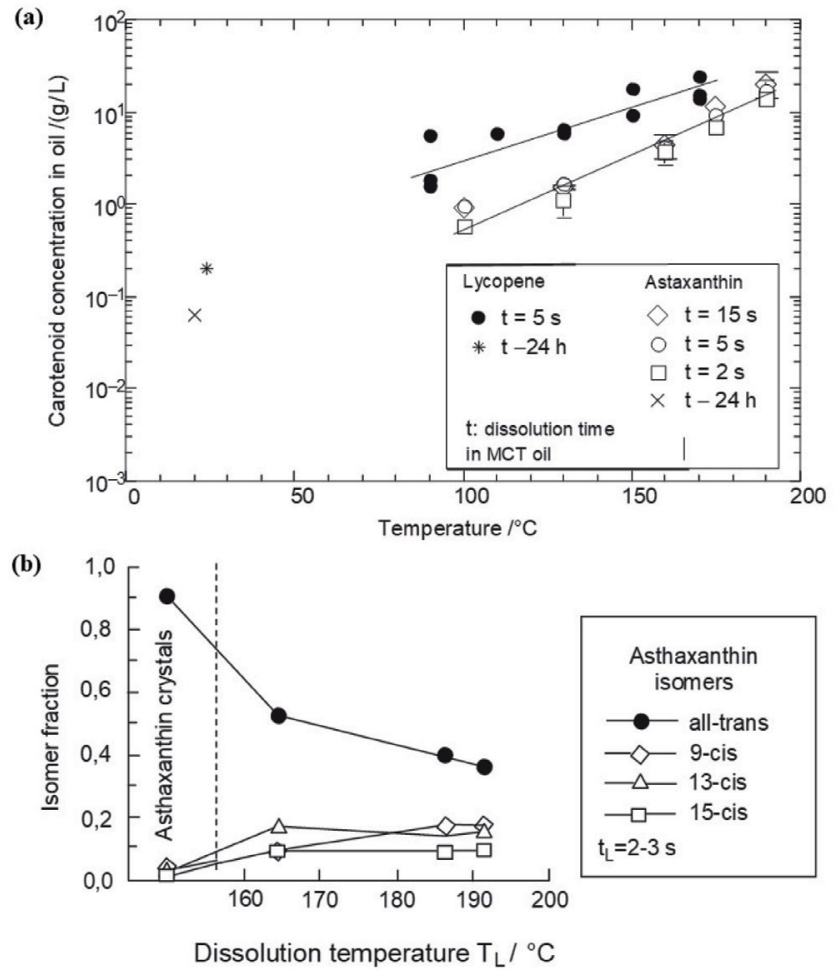

Figure 4. Effect of temperature on dissolution of different carotenoids. (a) Carotenoid concentration as a functional of dissolution time. (b) Isomeric fractions of astaxanthin after dissolution at different temperatures. Reproduced from Ribeiro et al. (2010).

lated in an $\mathrm{O} / \mathrm{W}$ nanoemulsion using high pressure homogenization, by Kim et al. (2012). They formulated stable nanoemulsions with mean droplet diameter between 160 to $190 \mathrm{~nm}$ using different glyceryl esters. 10\% (w/w) Astaxanthin extract from Fuji Chemicals was encapsulated in pure palm olein using a two-step homogenization process at 800 bars, with the resultant stability of nanoemulsions being dependent upon surfactant concentration, number of homogenization cycles and pressure (Affandi et al. 2011).

High-pressure homogenization is an effective method for astaxanthin encapsulation, however the release profile, stability and bioavailability are dependent upon optimum emulsifier concentration and homogenization speed.

\subsubsection{Lipid nanodispersions}

Astaxanthin is also encapsulated in different nanodipsersions, either using low energy methods or high energy methods. Affandi and co-workers did a comprehensive study of encapsulation of astaxanthin using nanodipsersions as the main carrier (Anarjan et al. 2014a; Anarjan et al. 2015; Anarjan et al. 2011a; Anarjan et al. 2014b; Anarjan et al. 2013; Anarjan and Ping Tan 2013; Anarjan and Tan 2013b; Anarjan and Tan 2013c; Anarjan and Tan 2013a; Anarjan and Tan 2013d; Anarjan et al. 2011b; Anarjan et al. 2012).

In most of these studies, highly purified astaxanthin $(>90 \%)$ was used to prepare the nanodispersions using a solvent displacement method. In this solvent displacement method (Fig. 5) astaxanthin was dissolved in a mixture of dichloromethane and acetone, with the aqueous phase containing the emulsifiers and stabilizer mixtures. The organic and aqueous phases are mixed with different high shear homogenizers, followed by solvent removal using rotor evaporation. The astaxanthin nanodispersions with particle sizes of $<100 \mathrm{~nm}$ were stable against different $\mathrm{pHs}$ except near the isoelectric point, salt $\left(\mathrm{NaCl}, \mathrm{CaCl}_{2}\right)$ and at different temperatures (Anarjan et al. 2014a). Similarly, response surface methodology was used to investigate the effect of different homogenization times $(0.5-20 \mathrm{~min})$ and speeds $(1,000-9,000 \mathrm{rpm})$ on nanodispersions via the solvent displacement method. The optimized conditions for astaxanthin encapsulation include homogenization at 6,000 rpm for $7 \mathrm{~min}$ (Anarjan et al. 2015).

Astaxanthin is also stabilized in nanodispersions using natural emulsifiers like sodium caseinate, using similar methodology to the solvent displacement method described previously. Multipleresponse optimization predicted stable nanodispersions at $30 \mathrm{MPa}$ with three passes (Anarjan et al. 2011a). The effect of different polysaccharides on stabilization of astaxanthin nanodispersions was investigated by Anarjan and Ping Tan (2013). They used 0.3\% (w/w) methyl cellulose, pectin, xanthan gum and gum Arabica as the main polysaccharides to stabilize $0.3 \%(\mathrm{w} / \mathrm{w})$ astaxanthin using a solvent evaporation technique. The molecular structure of polysaccharides directly affects the stability of astaxanthin. Gum Arabica addition not only improved the physical stability but also gave the smallest particle size (Anarjan and Ping Tan 2013). Moreover, the effect of different polysaccharides and gelatin was also investigated together with sucrose oleate and sodium caseinate as emulsifier to stabilize astaxanthin loaded nanodispersions. The addition of sodium caseinate in a gelatinized mixture improved the chemical stability of astaxanthin, while the addition of sucrose oleate gave the smallest nanodispersion particle size $(121 \mathrm{~nm})$ (Anarjan et al. 2014b). The same research group also uses natural antioxidants to improve the stability of astaxanthin in nanodispersions. The addition of $0.4 \%$ $\alpha$-tocopherol in combination with ascorbic acid improved the chemical stability of astaxanthin in nanodispersions (Anarjan et al. 2013).

Similarly, solid lipid nanoparticles can be produced using high pressure homogenization by melting the lipid at low temperature below its melting point. Li et al. (2016) encapsulated astaxanthin in solid lipid nanoparticles using stearic acid, glycerin monostearate, and glycerol distearates in soybean oil as the dispersed phase, while deionized water containing Tween 20 was used as the continuous phase. The different phases were mixed together using high pressure homogenization. $1 \%$ stearic acid was added as a lipid carrier that improved the particle size, and thermal stability of astaxanthin in nanoparticles.

\subsubsection{Membrane and microchannel emulsification}

Low energy methods are favorable for encapsulation of sensitive bioactive compounds. These methods improve the long-term storage stability of encapsulated compounds, however, scale-ability of the production process is still the limiting factor in low energy emulsification techniques. Among low energy methods, membrane and microchannel emulsification (MCE) are the prominent techniques.

Membrane emulsification is a process that forms emulsion by injecting a dispersed phase or premix through a microporous membrane into the continuous phase. In the former case, fine droplets are produced directly at the membrane/continuous phase interface, whereas in the latter case, pre-existing droplets are homogenized by passing premix through the membrane (Vladisavljevic et al. 2012). A microporous glass membrane called Shirasu porous glass (SPG) membrane was originally used as the emulsification device (Nakashima et al. 2000). The droplet size is largely depended upon membrane pore size (Nakashima et al. 2000). Typical monodispersed droplets are produced with coefficient of variation $(\mathrm{CV})$ of 


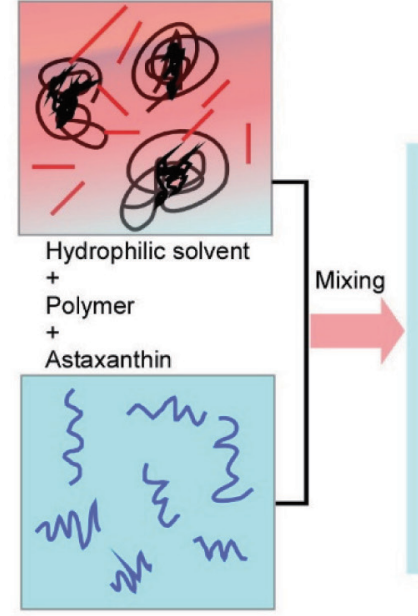

Water + Emulsifier

\section{Spontaneous droplet formation}

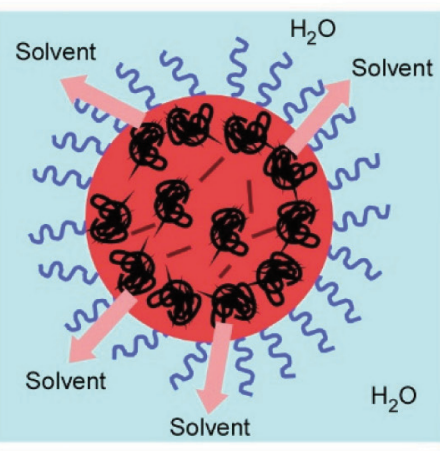

Macroscopic interface

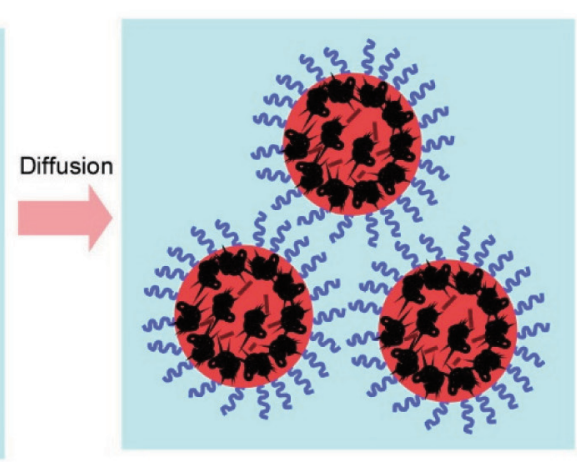

Nanodispersions

Figure 5. Schematic representation of the astaxanthin loaded nanodispersions formed through the solvent displacement method.

less than 10\% (Vladisavljevic et al. 2012). Membrane emulsification requires relatively small shear stress and low energy input $\left(10^{4}-10^{6} \mathrm{~J} \mathrm{~m}^{-3}\right)$ to prepare emulsions than conventional emulsification devices $\left(10^{6}-10^{8} \mathrm{~J} \mathrm{~m}^{-3}\right)$ (Schröder et al. 1998). A variety of materials are used to conduct membrane emulsification for the production of $\mathrm{O} / \mathrm{W}$ or $\mathrm{W} / \mathrm{O}$ emulsions. These includes uniform porous glass (Nakashima et al. 2000), polypropylene hollow fibres (Vladisavljevic et al. 2012), ceramics (Schröder and Schubert 1999), polytetrafloroethylene (Yamazaki et al. 2003) and silicon nitride (Zhu and Barrow 2005). The surface of the membrane must be completely wetted with continuous phase for production of monodisperse emulsions. Based upon geometry, there are a variety of membrane emulsification, such as dead end type (Arnot et al. 2000), cross flow type (Vladisavljević and Williams 2005), vibrating type (Zhu and Barrow 2005) and rotating type membrane emulsification (Joscelyne and Trägårdh 2000). Membrane emulsification can be used to produce particles from a wide variety of organic and inorganic materials, including hydrogels, polymers, inorganic oxides, metals and solid lipids (Vladisavljevic et al. 2012).

Ribeiro et al. (2005) encapsulated astaxanthin in $\mathrm{O} / \mathrm{W}$ emulsions using repeated premix membrane emulsification. They used $80 \%$ pure crystalline astaxanthin in mygliol as the dispersed phase, while the aqueous phase contained two different emulsifiers (Tween 20 and whey protein isolate in equal concentrations). The pressure in the membrane was varied between 5 to 15 bars and the dispersed phase fraction varied between $10 \%$ to $40 \%$. The premix $\mathrm{O} / \mathrm{W}$ emulsions were passed three times through apolyamide 6,6 membrane with pore size of $0.8 \mu \mathrm{m}$. Increased pressure and number of repetition resulted in narrow size droplet distribution. The total astaxanthin concentration in $\mathrm{O} / \mathrm{W}$ emulsions decreased to about $30 \%$ after three weeks of storage, while no coalescence was observed during the evaluated storage period (Ribeiro et al. 2005).

The term MCE was coined by Kawakatsu et al. (1997) and has the capability to form monodisperse emulsion droplets by using microchannel (MC) arrays precisely fabricated on single-crystal silicon microchips(Kawakatsu et al. 1997) or stainless steel microchips (Kobayashi et al. 2012). These MC arrays can be fabricated as microgrooves horizontally to the microchip surface (Kawakatsu et al. 1997) or vertically as straight-through microholes (Kobayashi et al. 2002). The grooved microchips exhibit low droplet productivity due to limited numbers of MCs, but is extremely productive in elucidating droplet generation behavior in MCs. The straight-thorough microchips consist of several hundreds of thousands of MCs and have monodisperse droplet productivity even at a dripping regime of $50 \mathrm{~mL} \mathrm{~h}^{-1}$ (Kobayashi et al. 2002).

Sugiura et al. (2001) proposed an interfacial tension-driven droplet formation mechanism to form channels with an elongated section. The model for predicting droplet diameter in MCE was also presented and is based on droplet formation mechanisms and experimental observation (Sugiura et al. 2002a; Sugiura et al. 2002b). Monodispersed emulsion droplets with diameters of $1 \mu \mathrm{m}$ to $500 \mu \mathrm{m}$ and coefficient of variation below $5 \%$ have been successfully formulated through MCE (Vladisavljevic et al. 2012). The MCE has been used to produce a range of encapsulated dispersions with improved properties, such as $\beta$-carotene (Neves et al. 2008), oleuropein (Souilem et al. 2014), $\gamma$-oryzanol(Khalid et al. 2017a), L-ascorbic acid (Khalid et al. 2015a; Khalid et al. 2014b), ascorbic acid derivatives (Khalid et al. 2014a), quercetin (Khalid et al. 2016), various mixtures of vitamin D (Khalid et al. 2015b; Khalid et al. 2015c) and astaxanthin (Khalid et al. 2017c).

Monodisperse O/W emulsions encapsulating different commercial extracts of astaxanthin (10-20\% astaxanthin) has been recently produced by MCE (Khalid et al. 2017c). The experimental setup consists of a module containing an asymmetric straight through MCE array plate with 13,752 discrete $10 \times 104 \mu \mathrm{m}$ microslots, connected to a circular microhole with a diameter of $10 \mu \mathrm{m}$, various peristaltic pumps for delivering dispersed and continuous phases and a microscopic video system for recording the droplet generation process. The dispersed phase constitutes different astaxanthin extracts in MCT oil without any ingredient addition and the dispersed phase is prepared at room temperature without any heating. The continuous phase contains $1 \%(\mathrm{w} / \mathrm{w})$ of a range of emulsifiers like modified lecithin, sodium caseinate, decaglycerol monolaurate, decaglycerol monolaurate and SDS. The MCE was conducted at a relative low dispersed phase flow rate of $1 \mathrm{mLh}^{-1}$. Successful MCE was conducted with a $d_{3,2}$ of $35-37 \mu \mathrm{m}$ and relative span factor $<0.25$. The astaxanthin encapsulation was highly dependent on the type of emulsifiers and the extract type used during MCE (Fig. 6). Better droplet productivity was achieved with $20 \%$ AstaReal astaxanthin with $1 \%(\mathrm{w} / \mathrm{w})$ decaglycerol monolaurate as the optimized emulsifier. The astaxanthin loaded $\mathrm{O} / \mathrm{W}$ emulsion droplets 


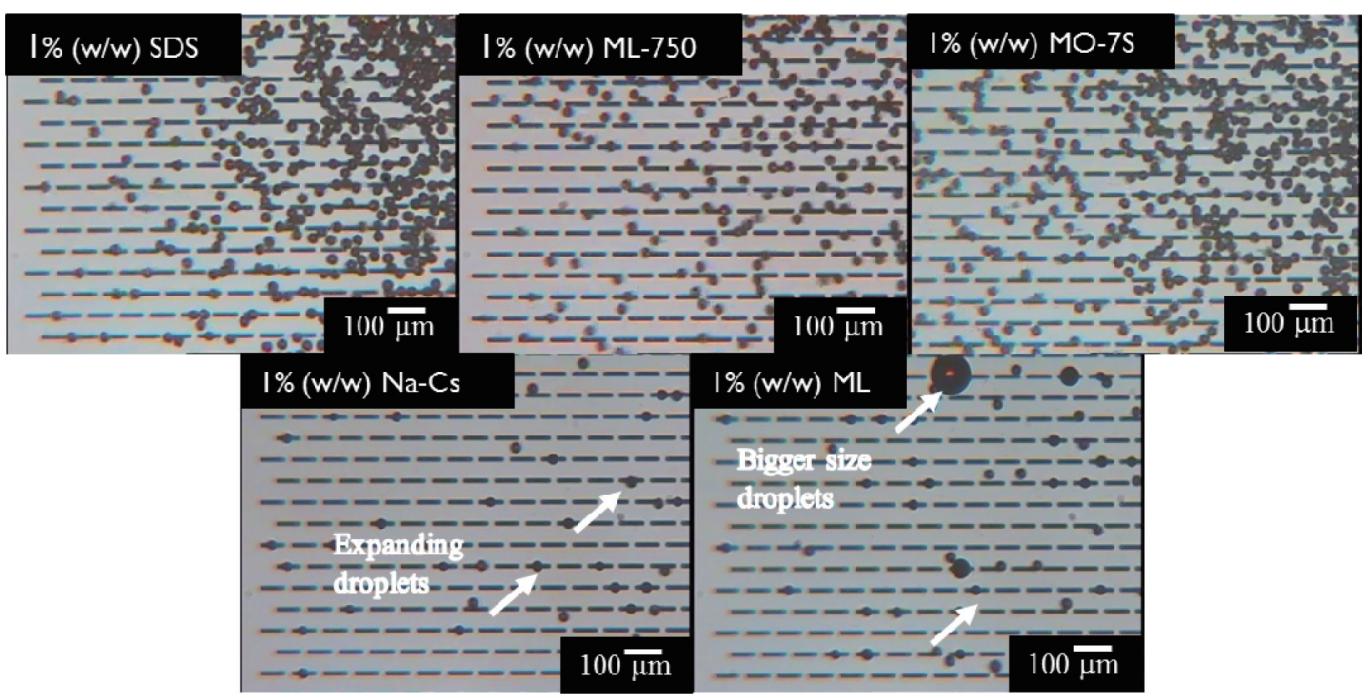

Figure 6. Effect of different emulsifiers on droplet generation from MCs. The dispersed phase constitutes AstaReal astaxanthin in MCT oil. ML-750 (decaglycerol monolaurate), MO-7S (decaglycerol monooleate), Na-Cs (sodium caseinate) and ML (modified lecithin). Reproduced from Khalid et al. (2017c).

remained stable at $25{ }^{\circ} \mathrm{C}$ with encapsulation efficiency of $>98 \%$ during 15 days of storage at room temperature (Khalid et al. 2017c).

\subsubsection{Encapsulation by phase inversion and high internal phase emulsions methods}

$\mathrm{O} / \mathrm{W}$ emulsions may undergo phase inversion to $\mathrm{W} / \mathrm{O}$ emulsions during heating and in the presence of ethoxylated non-ionic emulsifiers. At phase inversion temperatures, the hydrophilic and lipophilic properties of emulsifier are well balanced and nullify the interfacial activity of oil and water phases. Emulsification at phase inversion temperatures is called the phase inversion emulsification method or PIT method. The PIT method has the ability to produced emulsions with droplet diameter of $100 \mathrm{~nm}$ with an arrow size. The stability of the resultant emulsions was depended upon storage temperature and rapid cooling is required soon after producing the emulsions (Rao and McClements 2010).

However, there are not many studies reporting encapsulation of astaxanthin using the PIT method for food grade applications. Ribeiro and Schubert (2004)reported nanosized carotenoid loaded $\mathrm{O} / \mathrm{W}$ emulsions encapsulating lycopene and astaxanthin for nonfood grade applications. They used cetostearyl poly(oxyethylene (12) glycol) and glyceryl monostearate as the emulsifying agents to formulated $\mathrm{O} / \mathrm{W}$ emulsions using the PIT method. The composition included dissolution of astaxanthin and lycopene in dycapryl ether, which served as the oil phase. The emulsions were initially formulated at $74{ }^{\circ} \mathrm{C}$ with rapidly cooling at $25^{\circ} \mathrm{C}$. The $d_{3,2}$ of the emulsions were $80 \mathrm{~nm}$, while the dispersity of the emulsions was between 40 and $200 \mathrm{~nm}$. The total astaxanthin and lycopene concentration was around 0.3 and $3.5 \mathrm{~g} \mathrm{~L}^{-1}$ with no significant degradation of astaxanthin and lycopene (Ribeiro and Schubert 2004).

Particle stabilized emulsions are becoming more widely utilized as nutraceutical carries in both food and dietary supplements(Tan et al. 2017). These emulsions have outstanding stability, palatability and bioavailability(Dickinson 2010). High internal phase emulsions (HIPEs) with volume fractions exceeding 0.74 have numerous applications and served as template for gels, scaffolds and nutraceutical matrices(Grant et al. 2010Patel et al. 2014). The properties of HIPEs can easily be tuned in formulations with high concentration of nutraceuticals and with different rheological properties(Ribeiro and Cruz 2005). The thick interfacial layer around the droplets prevent oxidation, while the low water fraction in HIPEs extend the shelf life of emulsions and also improved gastrointestinal stability(Tan et al. 2017).

Ribeiro and Cruz (2005) formulated highly concentrated emulsions encapsulating lycopene and astaxanthin using high pressure homogenization. They concentrated the volume fraction of the dispersed phase up to $94 \%$ by removing the aqueous phase using centrifugation up to $38,000 \mathrm{~g}$. Moreover, the concentrated emulsions were called as "biliquid foam". The droplet size of the biliquid foams were changed by changing the emulsifier-to-oil ratio. The droplet size varied between 100 to $800 \mathrm{~nm}$ by varying the dispersed phase concentration from 10 to $50 \%$ (Fig. 7). After concentration and centrifugation, the biliquid foam shows a transparent and elastic structure. Moreover, no coalescence of the droplets was observed and $\mathrm{O} / \mathrm{W}$ concentrated emulsions have a good viscoelastic profile (Ribeiro and Cruz 2005).

\subsubsection{Liposomes and nanoparticles}

Liposomes are microscopic phospholipid bubbles with a bilayered membrane structure. Liposomes are mostly used to deliver lipophilic drugs, but liposomes have numerous applications in the fields of gene delivery and cancer therapy. Astaxanthin can be encapsulated in liposomes as a targeted drug vehicle. The double layer of liposomes is normally made from lecithins of different purities. Upon hydration and input of mechanical energy lecithin molecules orient themselves in double layers, with the lipophilic part toward the center and the hydrophilic part toward the outer surface. Liposomes greatly increase the bioavailability of astaxanthin and other lipophilic bioactives. The size of the liposomes can be adjusted using mechanical forces and a range of production methods, and have typical diameters of less than $100 \mathrm{~nm}$ with clear physical appearance.

The solubility of astaxanthin in phospholipids is very low, and dissolution cannot be performed at higher temperatures, since phospholipids decomposed at $180{ }^{\circ} \mathrm{C}$. To avoid decomposition, astaxanthin and phospholipids are dispersed in an organic phase 


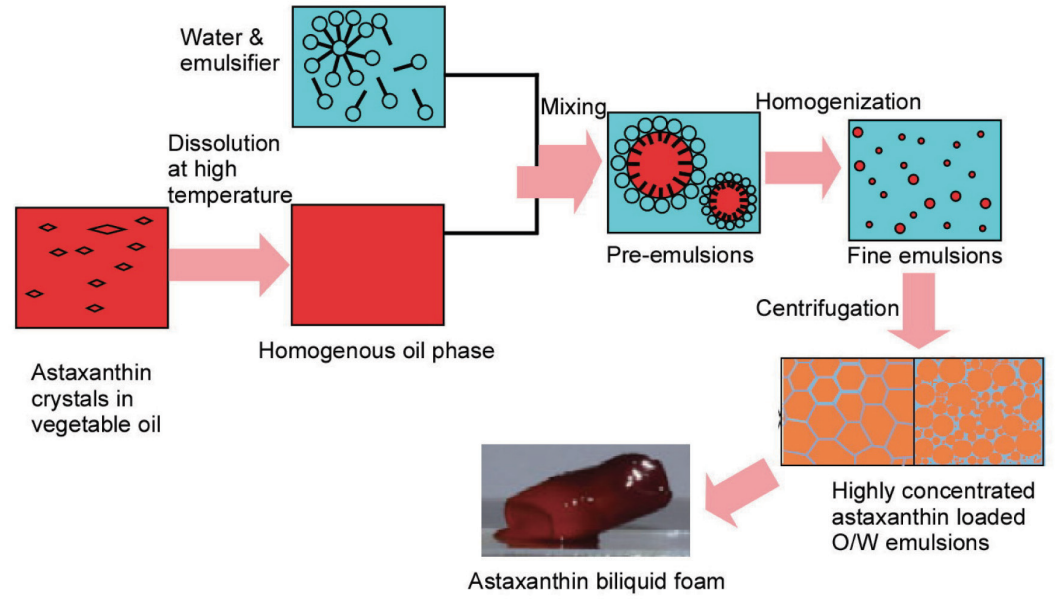

Figure 7. Schematic presentation of astaxanthin loaded biliquid foams. Reproduced with modification from Ribeiro and Cruz (2005).

and then the solvent is removed under reduced pressure. Recently, Kamezaki et al. (2016) encapsulated astaxanthin in liposomes together with different vitamin E derivatives. In this system the antioxidant activity increased significant when astaxanthin was coadministrated with vitamin $\mathrm{E}$.

Astaxanthin loaded nanoparticles have droplet sizes between 100 to $300 \mathrm{~nm}$ (Aizuddin et al. 2014; Bharathiraja et al. 2016). Mostly, nanoparticles are formulated using a solvent displacement method or emulsion evaporation method. Higuera-Ciapara et al. (2004) encapsulated astaxanthin in a chitosan matrix using a solvent evaporation technique. They used glutaraldehyde as the cross-linking agent and the microcapsules were chemically stable over a period of eight weeks. Similarly, Tachaprutinun et al. (2009) encapsulated astaxanthin in polymeric nanospheres by a solvent displacement method. They compared the three polymers poly(vinylalcohol-co-vinyl-4-methoxycinnamate), poly(ethylene oxide)-4-methoxycinnamoylphthaloylchitosan and ethylcellulose, and among these poly(ethylene oxide)-4-methoxycinnamoylphthaloylchitosan nanoparticles shows $98 \%$ encapsulation efficiency of astaxanthin with loading efficiency of $40 \%(\mathrm{w} / \mathrm{w})$. In another study, Tamjidi et al. (2014) formulated food grade astaxanthin-loaded nanostructured lipid carriers using Tween 20 and lecithin as the emulsifiers. The lipid nanocarriers were oleic acid and glyceryl behenate, while a melt emulsification-sonication technique was used to formulate the nanocarriers. Oleic acid was a better carrier than glyceryl behenate and exhitbited good particle size and dispersity index. Kittikaiwan et al. (2007) encapsulated astaxanthin using $80 \mathrm{~mol} \%$ deacethylated chitosan and the astaxanthin was coated with chitosan five times in the form of multilayers to form a thin chitosan film. The chitosan capsules had uniform shape with diameters from 0.35 to $0.5 \mathrm{~cm}$ with $100 \mu \mathrm{m}$ film thickness. The chitosan film protected the astaxanthin from degradation.

Astaxanthin has also been encapsulated using particle formation techniques based on supercritical fluids, such as rapid expansion of supercritical solutions (RESS). The Supercritical Fluid Extraction of Emulsions (SFEE) technique combines the efficiency of supercritical fluid as the antisolvent for the formation of particles in combination with emulsification processes to formulate the nanoparticles (Cocero et al. 2009). Astaxanthin from shrimp-residue was encapsulated by Mezzomo et al. (2012) via the SFEE technique using the modified starch Hi-Cap 100 as the wall material and dichloromethane as the primary solvent.
Astaxanthin was also encapsulated in $\beta$-cyclodextrin inclusion complex (Chen et al. 2007) and the heat stability of the inclusion complex was greatly enhanced, moreover the aqueous solubility of the inclusion complex was slightly increased. Similar results were also reported by Kim et al. (2010), when they used an inclusion complex of astaxanthin with $\beta$-cyclodextrin in a ratio of 1:200. The storage stability, antioxidant activity and radical scavenging activity of astaxanthin loaded in hydroxypropyl- $\beta$-cyclodextrin inclusion complex was improved in comparison to free astaxanthin (Yuan et al. 2013).

\subsubsection{Astaxanthin encapsulation by drying methods}

Microencapsulation of astaxanthin in different powders was obtained either by spray drying or freeze drying. Different coating/ wall materials were used to microencapsulate astaxanthin, including soluble corn fiber, whey protein isolates, sodium caseinate, maltodextrin, gum arabica and chitosan (Higuera-Ciapara et al. 2004; Bustos-Garza et al. 2013; Shen and Quek 2014). Shen and Quek (2014) used spray drying to encapsulate astaxanthin in wall material composed of blends of milk proteins and soluble corn fiber. Firstly, fine emulsions were produced using a two-step homogenization process and later the fine emulsions were spray dried using an atomizing spray nozzle with a rotational speed of 25,000 $\mathrm{n} \mathrm{min}^{-1}$. The reconstituted emulsions showed good physical stability with an encapsulation efficiency of about $95 \%$. The astaxanthin oleoresin from Haematococcus pluvialis was dispersed in aqueous solutions with soy lecithin as emulsifier and later spray dried using gum arabica and whey protein isolates in combination with inulin or maltodextrin. Whey protein alone or combined with gum arabica exhibited the best encapsulation efficiency of $61.2-70.1 \%$ (Bustos-Garza et al. 2013). Most of the microencapsulated spray dried astaxanthin powders showed first order degradation kinetics, which depended upon the extraction procedure and core wall to oil ratios (Bustos-Garza et al. 2013; Pu et al. 2011).

Freeze drying methodology was applied mostly in solvent displacement or solvent evaporation formulations with a maximum payload of over $85 \%$ (Tachaprutinun et al. 2009). Gomez-Estaca et al. (2016) encapsulated shrimp waste extracted astaxanthin using complex coacervation with gelatin-cashew gum as core wall material followed by freeze drying to get the astaxanthin powder, although the encapsulation efficiency from was rather low at only 
$60 \%$. Moreover, the microencapsulated powder retarded the degradation of astaxanthin during the evaluated storage time (GomezEstaca et al. 2016).

\section{Bioavailability of astaxanthin encapsulated formulations}

Bioavailability of non-encapsulated astaxanthin has mostly been conducted as Haematococcus meal, with results indicating that a daily intake of $5 \mathrm{mg}$ astaxanthin in a capsular form is rapidly metabolized over a period of $24 \mathrm{~h}$. The intestinal absorption of carotenoids depends upon different factors like carotenoid type, dosage type and level, matrix of delivery, molecular linkage, genetic factors and various interactions among these factors (Parada and Aguilera 2007). The various steps of digestion, absorption and plasma transport of dietary carotenoids in mammals have been reviewed (Furr, and Clark, 1997). In plasma, differentnon-polar carotenoids such as $\beta$-carotene and lycopene are mostly transported by very low-density lipoproteins (VLDLs) and low-density lipoproteins (LDLs), while polar carotenoids, such as zeaxanthin or lutein, are more likely to be transported by LDLs and high-density lipoproteins (HDLs).Astaxanthin is primarily transported in plasma via lipoproteins (Osterlie et al., 2000).

In vitro cell models are effective for investigating the cellular uptake of encapsulated astaxanthin by intestinal simulated fluids (Anarjan and Tan 2013a; Anarjan et al. 2011b; Anarjan et al. 2012; Khalid et al. 2017b). Bioaccessibility of encapsulated astaxanthin is highly depended upon emulsifiers.Recently, Khalid et al. (2017b) evaluated the bioaccessibility of astaxanthin nanoemulsions in simulated gastrointestinal fluids using modified lecithin and sodium caseinate as emulsifiers. The bioaccessibility (Fig. 8a) of encapsulated astaxanthin was significantly higher in modified lecithin $(33 \%)$ in comparison to sodium caseinate $(6 \%)$. Colloidal astaxanthin composed of different mixtures of polysorbate 20 , gum arabica and sodium caseinate improved the cellular uptake of astaxanthin in human colon carcinoma HT-29 cell lines (Anarjan et al. 2012). The results agree with previous findings of Ribeiro et al. (2004) and Ribeiro et al. (2006), where mixtures of whey proteins in combination with Tween 20 or sucrose laurate significantly increased astaxanthin or lycopene cellular uptake from emulsified forms. In a similar cell line model (HT-29), astaxanthin cellular uptake increased by $2981 \mathrm{fmol} / \mathrm{cell}$, when astaxanthin was delivered in nanodispersed form, formulated through a precipitation and condensation process (Anarjan et al. 2011b). Anarjan and Tan (2013a) evaluated the cellular uptake of encapsulated astaxanthin in selected food systems (skimmed milk, deionized water and orange juice) using T-29 cell lines. The cellular uptake was higher in skimmed milk (Fig. 8b) when compared with orange juice and deionized water. Moreover, the bioavailability was also lowest in diluted orange juice. Milk proteins and dietary fats have positive effects on cellular uptake and on bioavailability of carotenoids (Castenmiller and West 1998). Microencapsulating astaxanthin in calcium alginate matrix through emulsion gelation technology improved the solubility of astaxanthin and these microcapsules also exhibited good cytostatic activity on adipose-derived stem cells(Zhang et al. 2017).

Liposomal encapsulation also improved the cellular uptake of astaxanthin, lycopene and $\beta$-carotene when formulated with phosphatidylcholine. The cellular uptake was more effective than that for emulsified astaxanthin with Tween 20 (Fig. 8c). However, the effectiveness was similar to when a combined mixture of Tween 20 and Whey protein was used as emulsifiers in $\mathrm{O} / \mathrm{W}$ emulsions (Ribeiro et al. 2010).

\section{Conclusion and future perspectives}

Due to an excellent antioxidant profile and a range of observed health benefits, astaxanthin has been incorporated into a range of food and pharmaceutical matrices. However, astaxanthin is highly unstable and loses it functionality during some food processing steps or during storage. Encapsulation and emulsification are useful techniques to protect astaxanthin during storage and processing. The optimization of these techniques on industrial scale is important to increase the efficiency and productivity of the biological properties. Low energy emulsification methods need more optimization, since these are effective in controlling the droplet size and encapsulation efficiency of astaxanthin. Important parameters that affect the stability of encapsulated astaxanthin include the composition of matrix, type of emulsifiers and stabilizers and the concentration of astaxanthin in the delivery medium.

Extraction and quantification of astaxanthin in encapsulated samples can be challenging, particularly since most of the astaxanthin extracts contain esterified astaxanthin rather than free astaxanthin and also have complex matrices that need to be quantitatively removed. Finally, most bioavailability and digestion studies with encapsulated astaxanthin involve stimulated gastric fluids, or different in vitro models, which are only indicators of bioavailability. More accurate bioavailability determination requires testing in human subjects or at least anima 1 in vivo models to determine the effective bioavailability of specific encapsulation systems. Finally, for food grade applications formulations and ingredients are limited by both market and regulatory requirements, limiting the scope of methods and materials available for use in food systems. Further investigation and development of new food grade encapsulation materials is an important area of ongoing research.

\section{Acknowledgments}

Author NK acknowledges an Alfred Deakin Post-Doctoral Fellowship from Deakin University Australia.

\section{References}

Affandi, M., Julianto, T., and Majeed, A. (2011). Development and stability evaluation of astaxanthin nanoemulsion. Asian J. Pharm. Clin. Res. 4: 142-148.

Aizuddin, K.K., Nurlina, M., Khuriah, A., Foo, C., and Meor Mohd Affandi, M.M.R. (2014). Development of Astaxanthin-loaded biodegradable nanoparticles by nanoprecipitation method. Int. J. Pharm. Technol. 5: 5962-5972.

Ambati, R.R., Phang, S.M., Ravi, S., and Aswathanarayana, R.G. (2014). Astaxanthin: sources, extraction, stability, biological activities and its commercial applications-A review. Marine Drugs. 12: 128-152.

Anarjan, N., Jafarizadeh-Malmiri, H., Nehdi, I.A., Sbihi, H.M., Al-Resayes, S.I., and Tan, C.P. (2015). Effects of homogenization process parameters on physicochemical properties of astaxanthin nanodispersions prepared using a solvent-diffusion technique. Int. J. Nanomed. 10: 1109.

Anarjan, N., Jafarizadeh Malmiri, H., Ling, T.C., and Tan, C.P. (2014a). Effects of $\mathrm{pH}$, ions, and thermal treatments on physical stability of astaxanthin nanodispersions. Int. J. Food Prop. 17: 937-947.

Anarjan, N., Mirhosseini, H., Baharin, B.S., and Tan, C.P. (2011a). Effect of processing conditions on physicochemical properties of sodium caseinate-stabilized astaxanthin nanodispersions. LWT-Food Sci. Technol. 44: 1658-1665.

Anarjan, N., Nehdi, I.A., Sbihi, H.M., Al-Resayes, S.I., Malmiri, H.J., and Tan, C.P. (2014b). Preparation of astaxanthin nanodispersions using gela- 
(a)

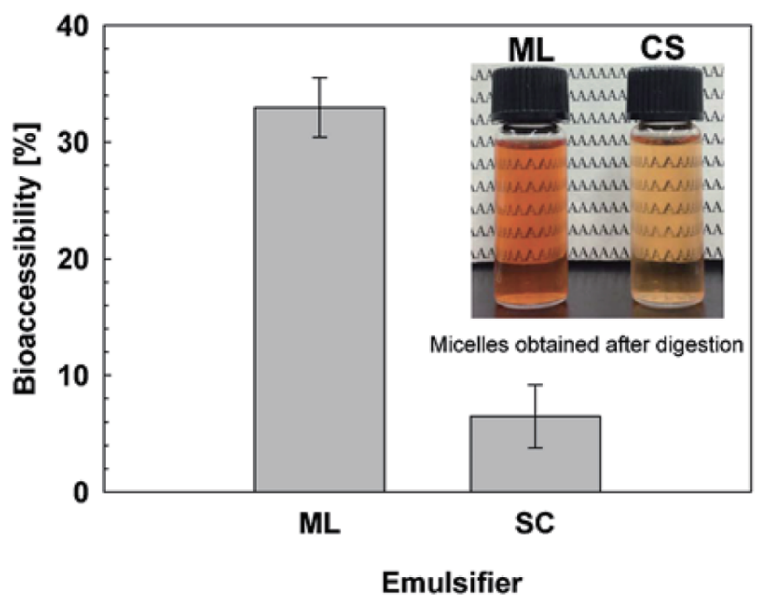

(b)

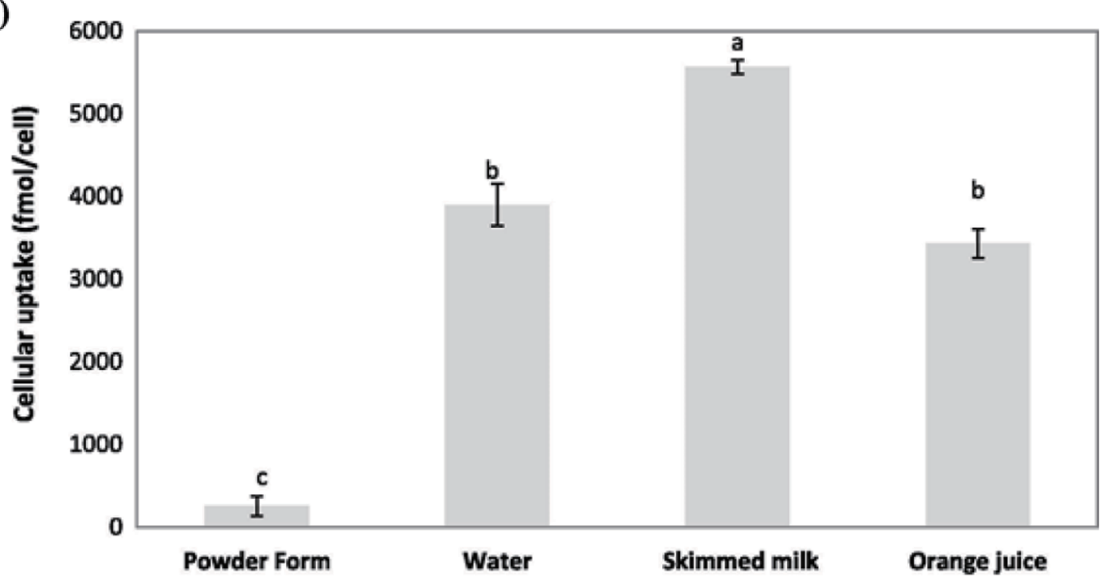

(c)

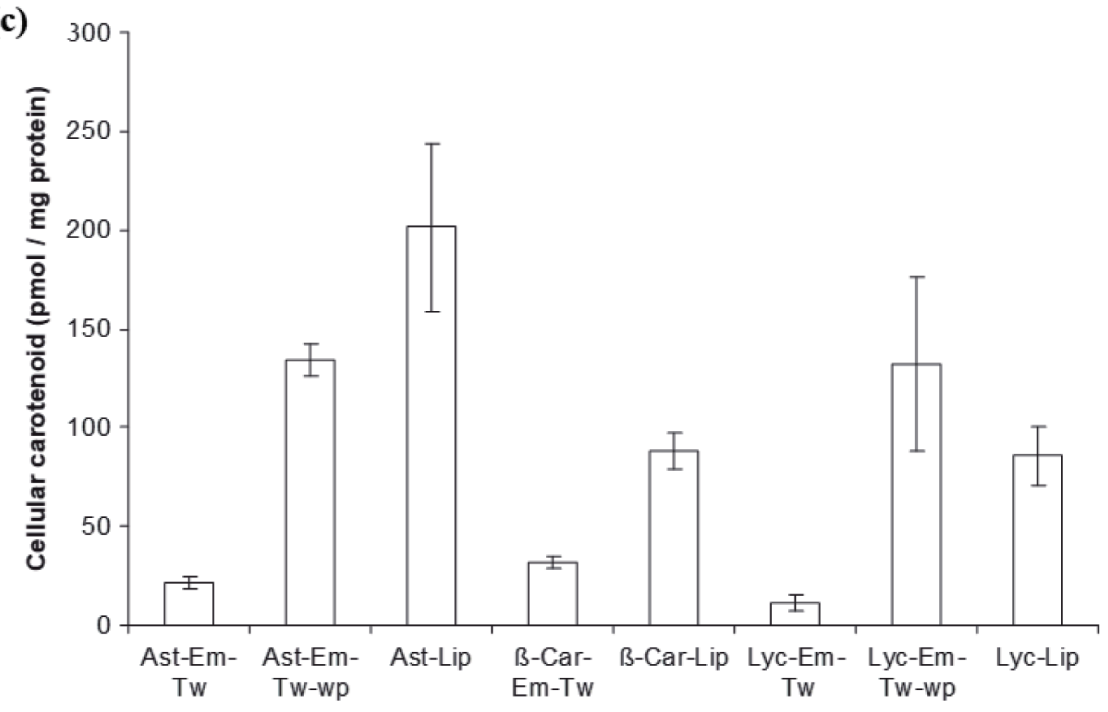

Carotenoid/ Formulations / Emulsifier

Figure 8. Studies depicting bioaccessibility and bioavailability of astaxanthin in emulsified forms. (a) Bioaccessibility study of emulsified astaxanthin with different emulsifiers, ML (modified lecithin) and CS (sodium caseinate), (b) Bioavailability studies in HT-29 cell lines of nanodispsersed astaxanthin in food systems, and (c) Cellular uptake of carotenoids in different emulsified forms, Ast-Em.Tw (Tween 20 stabilized astaxanthin nanoemulsions), Ast-Em.wp (Whey proteins stabilized astaxanthin nanoemulsions), Ast-lip (astaxanthin loaded lipsomes), $\beta$-car and Lyc stands $\beta$-carotene and lycopene (Anarjan and Tan 2013a; Khalid et al. 2017b; Ribeiro et al. 2010). 
tin-based stabilizer systems. Molecules. 19: 14257-14265.

Anarjan, N., Nehdi, I.A., and Tan, C.P. (2013). Protection of astaxanthin in astaxanthin nanodispersions using additional antioxidants. Molecules. 18: 7699-7710.

Anarjan, N., and Tan, C.P. (2013). Physico-chemical stability of astaxanthin nanodispersions prepared with polysaccharides as stabilizing agents. Int. J. Food Sci. Nutr. 64: 744-748.

Anarjan, N., and Tan, C.P. (2013a). Chemical stability of astaxanthin nanodispersions in orange juice and skimmed milk as model food systems. Food Chem. 139: 527-531.

Anarjan, N., and Tan, C.P. (2013b). Developing a three component stabilizer system for producing astaxanthin nanodispersions. Food Hydrocolloid. 30: 437-447.

Anarjan, N., and Tan, C.P. (2013c). Effects of selected polysorbate and sucrose ester emulsifiers on the physicochemical properties of astaxanthin nanodispersions. Molecules. 18: 768-777.

Anarjan, N., and Tan, C.P. (2013d). Effects of storage temperature, atmosphere and light on chemical stability of astaxanthin nanodispersions. J. Am. Oil Chem. Soc. 90: 1223-1227.

Anarjan, N., Tan, C.P., Ling, T.C., Lye, K.L., Malmiri, H.J., Nehdi, I.A., Cheah, Y.K., Mirhosseini, H., and Baharin, B.S. (2011b). Effect of organic-phase solvents on physicochemical properties and cellular uptake of astaxanthin nanodispersions. J. Agric. Food Chem. 59: 8733-8741.

Anarjan, N., Tan, C.P., Nehdi, I.A., and Ling, T.C. (2012). Colloidal astaxanthin: Preparation, characterisation and bioavailability evaluation. Food Chem. 135: 1303-1309.

Arnot, T., Field, R., and Koltuniewicz, A. (2000). Cross-flow and dead-end microfiltration of oily-water emulsions: part II. Mechanisms and modelling of flux decline. J. Membrane Sci. 169: 1-15.

Augusti, P.R., Quatrin, A., Somacal, S., Conterato, G.M., Sobieski, R., Ruviaro, A.R., Maurer, L.H., Duarte, M.M., Roehrs, M., and Emanuelli, T. (2012). Astaxanthin prevents changes in the activities of thioredoxin reductase and paraoxonase in hypercholesterolemic rabbits. J.Clin. Biochem.Nutr. 51: 42-49.

Bharathiraja, S., Manivasagan, P., Quang Bui, N., Oh, Y.-O., Lim, I.G., Park, S., and Oh, J. (2016). Cytotoxic induction and photoacoustic imaging of breast cancer cells using astaxanthin-reduced gold nanoparticles. Nanomaterials. 6: 78

Boussiba, S., and Vonshak, A. (1991). Astaxanthin accumulation in the green alga Haematococcus pluvialis. Plant Cell Physiol. 32: 10771082.

Bustos-Garza, C., Yáñez-Fernández, J., and Barragán-Huerta, B.E. (2013). Thermal and $\mathrm{pH}$ stability of spray-dried encapsulated astaxanthin oleoresin from Haematococcus pluvialis using several encapsulation wall materials. Food Res. Int. 54: 641-649.

Castenmiller, J.J., and West, C.E. (1998). Bioavailability and bioconversion of carotenoids. Ann. Rev. Nutr. 18: 19-38.

Chen, X., Chen, R., Guo, Z., Li, C., and Li, P. (2007). The preparation and stability of the inclusion complex of astaxanthin with $\beta$-cyclodextrin. Food Chem. 101: 1580-1584.

Chew, B., Park, J., Wong, M., and Wong, T. (1998). A comparison of the anticancer activities of dietary beta-carotene, canthaxanthin and astaxanthin in mice in vivo. Anticancer Res. 19: 1849-1853.

Chew, B.P., and Park, J.S. Carotenoid action on the immune response. J. Nutr 134: 257S-261S.

Cocero, M.J., Martín, Á., Mattea, F., and Varona, S. (2009). Encapsulation and co-precipitation processes with supercritical fluids: fundamentals and applications. J. Supercritical Fluids. 47: 546-555.

Dickinson, E. (2010). Food emulsions and foams: stabilization by particles. Cur. Opin. Colloid Interface Sci. 15: 40-49.

Gomez-Estaca, J., Comunian, T., Montero, P., Ferro-Furtado, R., and Favaro-Trindade, C. (2016). Encapsulation of an astaxanthin-containing lipid extract from shrimp waste by complex coacervation using a novel gelatin-cashew gum complex. Food Hydrocolloid. 61: 155-162.

Grant, N.C., Cooper, A.I., and Zhang, H. (2010). Uploading and temperature-controlled release of polymeric colloids via hydrophilic emulsion-templated porous polymers. ACS appl. Mat. Interface. 2 1400-1406.

Gross, G.J., and Lockwood, S.F. (2005). Acute and chronic administration of disodium disuccinate astaxanthin (CardaxTM) produces marked cardioprotection in dog hearts. Mol. Cell. Biochem. 272: 221-227.
Hama, S., Takahashi, K., Inai, Y., Shiota, K., Sakamoto, R., Yamada, A., Tsuchiya, H., Kanamura, K., Yamashita, E., and Kogure, K. (2012). Protective effects of topical application of a poorly soluble antioxidant astaxanthin liposomal formulation on ultraviolet-induced skin damage. J. Pharm. Sci. 101: 2909-2916.

Higuera-Ciapara, I., Felix-Valenzuela, L., and Goycoolea, F. (2006). Astaxanthin: a review of its chemistry and applications. Crit. Rev. Food Sci. Nutr. 46: 185-196.

Higuera-Ciapara, I., Felix-Valenzuela, L., Goycoolea, F., and ArgüellesMonal, W. (2004). Microencapsulation of astaxanthin in a chitosan matrix. Carbohydr Polym. 56: 41-45.

Johnson, E.A., and An, G.-H. (1991). Astaxanthin from microbial sources. Crit. Rev. Biotechnol. 11: 297-326.

Joscelyne, S.M., and Trägårdh, G. (2000). Membrane emulsification-a literature review. J. Membrane Sci. 169: 107-117.

Kamath, B.S., Srikanta, B.M., Dharmesh, S.M., Sarada, R., and Ravishankar, G.A. (2008). Ulcer preventive and antioxidative properties of astaxanthin from Haematococcus pluvialis. Eur. J. Pharmacol. 590: 387-395.

Kamezaki, C., Nakashima, A., Yamada, A., Uenishi, S., Ishibashi, H. Shibuya, N., Hama, S., Hosoi, S., Yamashita, E., and Kogure, K. (2016) Synergistic antioxidative effect of astaxanthin and tocotrienol by coencapsulated in liposomes. J. Clin. Biochem. Nutr. 59: 100-106.

Kawakatsu, T., Kikuchi, Y., and Nakajima, M. (1997). Regular-sized cell creation in microchannel emulsification by visual microprocessing method. J. Am. Oil Chem. Soc. 74: 317-321.

Khalid, N., Kobayashi, I., Neves, M.A., Uemura, K., Nakajima, M., and Nabetani, H. (2014a). Formulation of monodisperse water-in-oil emulsions encapsulating calcium ascorbate and ascorbic acid 2-glucoside by microchannel emulsification. ColloidSurf A. 459: 247-253.

Khalid, N., Kobayashi, I., Neves, M.A., Uemura, K., Nakajima, M., and Nabetani, H. (2014b). Monodisperse W/O/W emulsions encapsulating L-ascorbic acid: Insights on their formulation using microchannel emulsification and stability studies. Colloid Surf A. 458: 69-77.

Khalid, N., Kobayashi, I., Neves, M.A., Uemura, K., Nakajima, M., and abetani, H. (2015a). Monodisperse aqueous microspheres encapsulating high concentration of I-ascorbic acid: insights of preparation and stability evaluation from straight-through microchannel emulsification. Biosci Biotechnol Biochem. 79: 1852-1859.

Khalid, N., Kobayashi, I., Neves, M.A., Uemura, K., Nakajima, M., and Nabetani, H. (2016). Microchannel emulsification study on formulation and stability characterization of monodisperse oil-in-water emulsions encapsulating quercetin. Food Chemistry. 212: 27-34.

Khalid, N., Kobayashi, I., Neves, M.A., Uemura, K., Nakajima, M., and Nabetani, H. (2017a). Encapsulation of $\beta$-sitosterol plus $\gamma$-oryzanol in $\mathrm{O} / \mathrm{W}$ emulsions: Formulation characteristics and stability evaluation with microchannel emulsification. Food Bioproducts Process. 102: 222-232

Khalid, N., Kobayashi, I., Wang, Z., Neves, M.A., Uemura, K., Nakajima, M., and Nabetani, H. (2015b). Formulation characteristics of triacylglyc erol oil-in-water emulsions loaded with ergocalciferol using microchannel emulsification. RSC Adv. 5: 97151-97162.

Khalid, N., Kobayashi, I., Wang, Z., Neves, M.A., Uemura, K., Nakajima, M., and Nabetani, H. (2015c). Formulation of monodisperse oil-in-water emulsions loaded with ergocalciferol and cholecalciferol by microchannel emulsification: insights of production characteristics and stability. Int. J. Food Sci. Technol. 50: 1807-1814.

Khalid, N., Shu, G., Holland, B.J., Kobayashi, I., Nakajima, M., and Barrow, C.J. (2017b). Formulation and characterization of O/W nanoemulsions encapsulating high concentration of astaxanthin. Food Res Int 102: 364-371.

Khalid, N., Shu, G., Kobayashi, I., Nakajima, M., and Barrow, C.J. (2017c) Formulation and characterization of monodisperse $\mathrm{O} / \mathrm{W}$ emulsions encapsulating astaxanthin extracts using microchannel emulsification: Insights of formulation and stability evaluation. Colloid Surf B. 157: 355-365.

Kim, D.M., Hyun, S.S., Yun, P., Lee, C.H., and Byun, S.Y. (2012). Identification of an emulsifier and conditions for preparing stable nanoemulsions containing the antioxidant astaxanthin. Int. J. Cosmet Sci. 34: 64-73.

Kim, S., Cho, E., Yoo, J., Cho, E., Choi, S.J., Son, S.M., Lee, J.M., In, M.J., Kim D.C., and Kim, J.-H. (2010). $\beta$-CD-mediated encapsulation enhanced stability and solubility of astaxanthin. J. Korean Soc. Appl. Biol. Chem. 
53: 559-565.

Kim, Y.J., Kim, Y.A., and Yokozawa, T. (2009). Protection against oxidative stress, inflammation, and apoptosis of high-glucose-exposed proximal tubular epithelial cells by astaxanthin. J. Agric. Food Chem. 57: 8793-8797.

Kittikaiwan, P., Powthongsook, S., Pavasant, P., and Shotipruk, A. (2007). Encapsulation of Haematococcus pluvialis using chitosan for astaxanthin stability enhancement. Carbohydr polym. 70: 378-385.

Kobayashi, I., Nakajima, M., Chun, K., Kikuchi, Y., and Fukita, H. (2002). Silicon array of elongated through-holes for monodisperse emulsion droplets. Aiche J. 48: 1639-1644.

Kobayashi, I., Wada, Y., Hori, Y., Neves, M.A., Uemura, K., and Nakajima, M. (2012). Microchannel emulsification using stainless-steel chips: oil droplet generation characteristics. Chem. Eng. Technol. 35: 18651871.

Lemoine, Y., and Schoefs, B. (2010). Secondary ketocarotenoid astaxanthin biosynthesis in algae: a multifunctional response to stress. Photosynthesis Res. 106: 155-177.

Li, M., Zahi, M.R., Yuan, Q., Tian, F., and Liang, H. (2016). Preparation and stability of astaxanthin solid lipid nanoparticles based on stearic acid. Eur. J. Lipid Sci. Technol. 118: 592-602.

Lorenz, R.T., and Cysewski, G.R. (2000). Commercial potential for Haematococcus microalgae as a natural source of astaxanthin. Trend Biotechnol. 18: 160-167.

Manabe, E., Handa, O., Naito, Y., Mizushima, K., Akagiri, S., Adachi, S., Takagi, T., Kokura, S., Maoka, T., and Yoshikawa, T. (2008). Astaxanthin protects mesangial cells from hyperglycemia-induced oxidative signaling. J. Cell. Biochem. 103: 1925-1937.

Maoka, T., Tokuda, H., Suzuki, N., Kato, H., and Etoh, H. (2012). Anti-oxidative, anti-tumor-promoting, and anti-carcinogensis activities of nitroastaxanthin and nitrolutein, the reaction products of astaxanthin and lutein with peroxynitrite. Marine Drugs. 10: 1391-1399.

McClements, D.J. (2012). Nanoemulsions versus microemulsions: terminology, differences, and similarities. Soft Matter. 8: 1719-1729.

McClements, D.J., Decker, E.A., and Choi, S.J. (2014). Impact of environmental stresses on orange oil-in-water emulsions stabilized by sucrose monopalmitate and Iysolecithin. J. Agric. Food Chem. 62: 3257-3261.

McClements, D.J., and Rao, J. (2011). Food-grade nanoemulsions: formulation, fabrication, properties, performance, biological fate, and potential toxicity. Crit. Rev. Food Sci. Nutr. 51: 285-330.

Mezzomo, N., de Paz, E., Maraschin, M., Martín, Á., Cocero, M.J., and Ferreira, S.R. Supercritical anti-solvent precipitation of carotenoid fraction from pink shrimp residue: Effect of operational conditions on encapsulation efficiency. J. Supercritical Fluids 66: 342-349.

Miao, F., Lu, D., Li, Y., and Zeng, M. (2006). Characterization of astaxanthin esters in Haematococcus pluvialis by liquid chromatography-atmospheric pressure chemical ionization mass spectrometry. Anal. Biochem. 352: 176-181.

Monroy-Ruiz, J., Sevilla, M.-Á., Carrón, R., and Montero, M.J. (2011). Astaxanthin-enriched-diet reduces blood pressure and improves cardiovascular parameters in spontaneously hypertensive rats. Pharmacol. Res. 63: 44-50.

Naguib, Y.M. (2000). Antioxidant activities of astaxanthin and related carotenoids. J. Agric. Food Chem. 48: 1150-1154.

Nakano, M., Onodera, A., Saito, E., Tanabe, M., Yajima, K., Takahashi, J., and Van Chuyen, N. (2008). Effect of astaxanthin in combination with $\alpha$-tocopherol or ascorbic acid against oxidative damage in diabetic ODS rats. J. Nutr. Sci. Vitaminol. 54: 329-334.

Nakashima, T., Shimizu, M., and Kukizaki, M. (2000). Particle control of emulsion by membrane emulsification and its applications. Adv. Drug Deliv. Rev. 45: 47-56.

Neves, M.A., Ribeiro, H.S., Kobayashi, I., and Nakajima, M. (2008). Encapsulation of lipophilic bioactive molecules by microchannel emulsification. Food Biophysics. 3: 126-131.

Olaizola, M., and Huntley, M.E. (2003). Recent advances in commercial production of astaxanthin from microalgae. In: Fingerman, M. and Nagabhushanam, R. Biomaterials and Bioprocessing. Science Publishers.

Palozza, P., Torelli, C., Boninsegna, A., Simone, R., Catalano, A., Mele, M.C., and Picci, N. (2009). Growth-inhibitory effects of the astaxanthin-rich alga Haematococcus pluvialis in human colon cancer cells. Cancer Lett. 283: 108-117.

Patel, A.R., Rodriguez, Y., Lesaffer, A., and Dewettinck, K. (2014). High internal phase emulsion gels (HIPE-gels) prepared using food-grade components. RSC Adv. 4: 18136-18140.

$\mathrm{Pu}$, J., Bankston, J.D., and Sathivel, S. (2011). Developing microencapsulated flaxseed oil containing shrimp (Litopenaeus setiferus) astaxanthin using a pilot scale spray dryer. Biosyst Eng. 108: 121-132.

Rao, J., and McClements, D.J. (2010). Stabilization of phase inversion temperature nanoemulsions by surfactant displacement. J. Agric. Food Chem. 58: 7059-7066.

Ribeiro, H., Briviba, K., Rechkemmer, G., and Schubert, H. (2004). Zelluläre Aufnahme von flüssigen Lycopin-Formulierungen. German Nutr Soc. 6: 43.

Ribeiro, H., and Schubert, H. (2004). Lycopene enriched PIT emulsion. In: 3rd Euro fed lipid congress, Scotland.

Ribeiro, H.S., and Cruz, R.C. (2005). Biliquid foams containing carotenoids. Eng. Life Sci. 5: 84-88.

Ribeiro, H.S., Guerrero, J.M., Briviba, K., Rechkemmer, G., Schuchmann, H.P., and Schubert, H. (2006). Cellular uptake of carotenoid-loaded oil-in-water emulsions in colon carcinoma cells in vitro. J. Agric. Food Chem. 54: 9366-9369.

Ribeiro, H.S., Rico, L.G., Badolato, G.G., and Schubert, H. (2005). Production of $\mathrm{O} / \mathrm{W}$ emulsions containing astaxanthin by repeated premix membrane emulsification. J. Food Sci. 70: E117-E123.

Ribeiro, H.S., Schuchmann, H.P., Engel, R., Walz, E. and Briviba, K. (2010) Encapsulation of carotenoids. In: Zuidam, N.J. and Nedovic, V. (Ed.) Encapsulation technologies for active food ingredients and food processing. Springer Science, pp. 211-252.

Santos, S.D., Cahú, T.B., Firmino, G.O., de Castro, C.C., Carvalho Jr, L.B., Bezerra, R.S., and José Filho, L.L. (2012). Shrimp waste extract and astaxanthin: rat alveolar macrophage, oxidative stress and inflammation. J. Food Sci. 77: H141-H146.

Schröder, V., Behrend, O., and Schubert, H. (1998). Effect of dynamic interfacial tension on the emulsification process using microporous, ceramic membranes. J. ColloidInterface Sci. 202: 334-340.

Schröder, V., and Schubert, H. (1999). Production of emulsions using microporous, ceramic membranes. Colloid Surf A. 152: 103-109.

Shen, Q., and Quek, S.Y. (2014). Microencapsulation of astaxanthin with blends of milk protein and fiber by spray drying. J. Food Eng. 123 165-171.

Sotomayor-Gerding, D., Oomah, B.D., Acevedo, F., Morales, E., Bustamante, M., Shene, C., and Rubilar, M. (2016). High carotenoid bioaccessibility through linseed oil nanoemulsions with enhanced physical and oxidative stability. Food Chem. 199: 463-470.

Souilem, S., Kobayashi, I., Neves, M., Sayadi, S., Ichikawa, S., and Nakajima, M. (2014). Preparation of monodisperse food-grade oleuropeinloaded w/o/w emulsions using microchannel emulsification and evaluation of their storage stability. Food Bioprocess Technol. 7: 2014-2027.

Sugiura, S., Nakajima, M., Iwamoto, S., and Seki, M. (2001). Interfacial tension driven monodispersed droplet formation from microfabricated channel array. Langmuir. 17: 5562-5566.

Sugiura, S., Nakajima, M., and Seki, M. (2002a). Effect of channel structure on microchannel emulsification. Langmuir. 18: 5708-5712.

Sugiura, S., Nakajima, M., and Seki, M. (2002b). Prediction of droplet diameter for microchannel emulsification. Langmuir. 18: 3854-3859.

Suzuki, Y., Ohgami, K., Shiratori, K., Jin, X.-H., Ilieva, I., Koyama, Y., Yazawa, K., Yoshida, K., Kase, S., and Ohno, S. (2006). Suppressive effects of astaxanthin against rat endotoxin-induced uveitis by inhibiting the NF-kB signaling pathway. Exp. Eye Res. 82: 275-281.

Tachaprutinun, A., Udomsup, T., Luadthong, C., and Wanichwecharungruang, S. (2009). Preventing the thermal degradation of astaxanthin through nanoencapsulation. Int. J. Pharm. 374: 119-124.

Tamjidi, F., Shahedi, M., Varshosaz, J., and Nasirpour, A. (2014). Design and characterization of astaxanthin-loaded nanostructured lipid carriers. Innov. Food Sci. Emerg. Technol. 26: 366-374.

Tan, H., Zhao, L., Tian, S., Wen, H., Gou, X., and Ngai, T. (2017). Gelatin particle-stabilized high-internal phase emulsions for use in oral delivery systems: protection effect and in vitro digestion study. J. Agric. Food Chem. 65: 900-907. 
Visser, H., van Ooyen, A.J., and Verdoes, J.C. (2003). Metabolic engineering of the astaxanthin-biosynthetic pathway of Xanthophyllomyces dendrorhous. FEMS Yeast Res. 4: 221-231.

Vladisavljevic, G.T., Kobayashi, I., and Nakajima, M. (2012). Production of uniform droplets using membrane, microchannel and microfluidic emulsification devices. Microfluid Nanofluid. 13: 151-178.

Vladisavljević, G.T., and Williams, R.A. (2005). Recent developments in manufacturing emulsions and particulate products using membranes. Adv. Colloid Interface Sci. 113: 1-20.

Wiener, H., Drory, A., and Line, L. (2003). Astaxanthin from the microalga Haematococcus- a superb natural antioxidant for human health. Innov. Food Technol. 25: 28-32.

Yamazaki, N., Naganuma, K., Nagai, M., Ma, G.H., and Omi, S. (2003). Prep- aration of W/O (Water-in-Oil) emulsions using a PTFE (Polytetrafluoroethylene) membrane-A New emulsification device. J. Disper. Sci. Technol. 24: 249-257.

Yuan, C., Du, L., Jin, Z., and Xu, X. (2013). Storage stability and antioxidant activity of complex of astaxanthin with hydroxypropyl- $\beta$-cyclodextrin. Carbohydr Polym. 91: 385-389.

Zhang, X., Yin, W., Qi, Y., Li, X., Zhang, W., and He, G. (2017). Microencapsulation of astaxanthin in alginate using modified emulsion technology: Preparation, characterization, and cytostatic activity. Can. J. Chem. Eng. 95: 412-419.

Zhu, J., and Barrow, D. (2005). Analysis of droplet size during crossflow membrane emulsification using stationary and vibrating micromachined silicon nitride membranes. J. Membrane Sci. 261: 136-144. 